\title{
Deposition of Nb-Si-C Thin Films by Radio Frequency Magnetron Sputtering
}

\author{
Zifeng Li ${ }^{1,2}$, Guotan Liu ${ }^{1}$, Guanqi Liu ${ }^{1}$, Xiaoshuo Zhu ${ }^{3}$ and Yudong Fu ${ }^{1, *(D)}$ \\ 1 School of Material Science and Chemical Engineering, Harbin Engineering University, Harbin 150001, China; \\ 13664505207@163.com (Z.L.); liuguotan097@163.com (G.L.); liuguanqi.hit@gmail.com (G.L.) \\ 2 School of Mechanical Engineering, Heilongiiang Polytechnic, Harbin 150008, China \\ 3 School of Mechanical Engineering, Xinjiang University, Urumqi 830045, China; zhu-xiaoshuo@hrbeu.edu.cn \\ * Correspondence: fuyudong@hrbeu.edu.cn
}

Citation: Li, Z.; Liu, G.; Liu, G.; Zhu, X.; Fu, Y. Deposition of Nb-Si-C Thin Films by Radio Frequency Magnetron Sputtering. Coatings 2021, 11, 524. https://doi.org/10.3390/ coatings11050524

Academic Editor: George E. Stan

Received: 23 February 2021

Accepted: 26 April 2021

Published: 29 April 2021

Publisher's Note: MDPI stays neutral with regard to jurisdictional claims in published maps and institutional affiliations.

Copyright: (c) 2021 by the authors. Licensee MDPI, Basel, Switzerland. This article is an open access article distributed under the terms and conditions of the Creative Commons Attribution (CC BY) license (https:// creativecommons.org/licenses/by/ $4.0 /)$.

\begin{abstract}
Nb}$-Si-C thin films were deposited onto $\mathrm{Si}(001)$ substrates by radio frequency (RF) magnetron sputtering using individual $\mathrm{Nb}, \mathrm{Si}$, and $\mathrm{C}$ targets. The effects of varying the sputtering power on the phase composition of the new thin films were studied. The structure, chemical components, and morphology of the thin films were characterized by $\mathrm{X}$-ray diffraction, $\mathrm{X}$-ray photoelectron spectroscopy, scanning electron microscopy, and atomic force microscopy. The experimental results and first-principles calculations indicate that a new MAX phase $\left(\mathrm{Nb}_{4} \mathrm{SiC}_{3}\right)$ can be synthesized at a sputtering power of $65 \mathrm{~W}$. The four-point probe test showed that the resistivity of the film containing $\mathrm{Nb}_{4} \mathrm{SiC}_{3}$ phase was $0.99 \mu \Omega \cdot \mathrm{m}$. A nano-indentation test showed that the hardness of the film containing $\mathrm{Nb}_{4} \mathrm{SiC}_{3}$ phase was $15 \mathrm{GPa}$, and the elastic modulus was $200 \mathrm{GPa}$.
\end{abstract}

Keywords: $\mathrm{Nb}$-Si-C system; radio frequency magnetron sputtering; $\mathrm{MAX}$ phase; $\mathrm{Nb}_{4} \mathrm{SiC}_{3}$

\section{Introduction}

The group of ternary layered ceramics known as the MAX phases not only have the electrical conductivity and heat conduction of metals but also the high elastic modulus, high temperature resistance, low thermal expansion coefficient, and the oxidation and corrosion resistance of ceramics [1-3]. Bulk MAX phases are used to make high-temperature components, foil bearings, burner nozzles, rubber molds, and metal-cutting tools [4]. MAX phase films are used for nuclear fuel cladding, high-temperature-resistant coatings, electrical components, and in other fields [5].

MAX phases have the structure $\mathrm{M}_{n+1} \mathrm{AX}_{n}$, where $n=1-3, \mathrm{M}$ is an early transition metal, $\mathrm{A}$ is an A-group element, and $\mathrm{X}$ is either $\mathrm{C}$ or $\mathrm{N}$. The MAX phase materials are a group of $60+$ ternary carbides and nitrides [6]. They have a layered structure with hexagonal symmetry $(\mathrm{P} 63 / \mathrm{mmc})$. In the MAX phases, near-close-packed layers of transition-metal carbide and/or nitride are interleaved with layers of a pure A-group. In the $\mathrm{M}_{2} \mathrm{AX}$ phases, A-layers are separated by two M-layers; in the $\mathrm{M}_{3} \mathrm{AX}_{2}$ phases, A-layers are separated by three M-layers; and in the $\mathrm{M}_{4} \mathrm{AX} \mathrm{X}_{3}$ phases, A-layers are separated by four M-layers [7].

Thin-film deposition of the MAX phases has been studied for many years, with physical vapor deposition and chemical vapor deposition as two main approaches. In recent years, sputtering has become the most popular method for synthesis of MAX phase thin films. There are two different methods for sputtering: from individual $\mathrm{M}, \mathrm{A}$, and $\mathrm{C}$ targets or from compound targets. The former is mainly used in the laboratory because the effects of different constituent elements on the structure and properties of the final products can be investigated easily and efficiently. The latter uses a single compound target for sputtering; the preparation process is relatively simple and has good repeatability, but it often leads to the problem of large deviation between the product and the chemical composition of the target material. 
To date, many MAX phase thin films have been synthesized, particularly in the Ti-SiC [8-10], Ti-Al-N [11-14], Ti-Al-C [15-17], Ti-Ge-C [18], Cr-Al-C [19,20], V-Al-C [21], and $\mathrm{Nb}-\mathrm{Al}-\mathrm{C}$ [22] systems; however, there have been few reports on the preparation of the $\mathrm{Nb}$-Si-C system. Researchers have prepared $\mathrm{Nb}-\mathrm{Si}-\mathrm{C}$ thin films by magnetron sputtering from individual $\mathrm{Nb}, \mathrm{Si}$, and $\mathrm{C}$ targets and obtained a mixture of $\mathrm{NbC}, \mathrm{SiC}$, and $\mathrm{NbSi}$ phases. The films exhibit nanocrystalline and amorphous structures. The segregation of $\mathrm{Si}$ at the $\mathrm{NbC}$ grain boundary will hinder the diffusion of $\mathrm{Nb}$ and $\mathrm{C}[23,24]$. They also found that the change of silicon content in the film has a great effect on the microstructure and properties of the film [25].

In recent years, many researchers have used computational materials science to predict the stability of MAX phase and their properties. The most widely used of these is density functional theory (DFT) [26-29]. According to DFT, in the $\mathrm{Nb}-\mathrm{Si}-\mathrm{C}$ system, only $\mathrm{Nb}_{4} \mathrm{SiC}_{3}$ is stable [30]. The theoretical existence of $\mathrm{Nb}_{4} \mathrm{SiC}_{3}$ is a metal and exhibits covalent nature. Moreover, the hardness of $\mathrm{Nb}_{4} \mathrm{SiC}_{3}$ is much higher than $\mathrm{Nb}_{4} \mathrm{AlC}_{3}$; meanwhile, it is more ductile than $\mathrm{Nb}_{4} \mathrm{AlC}_{3}$. Its high hardness and bulk modulus are due to the covalent bonding in $\mathrm{Nb}_{4} \mathrm{SiC}_{3}$ [31]. To sum up, the $\mathrm{Nb}-\mathrm{Si}-\mathrm{C}$ system may have excellent electrical, optical, and mechanical properties. The $\mathrm{Nb}-\mathrm{Si}-\mathrm{C}$ film has the potential to be a material with low electrical resistance and high wear resistance [32]. It also has the potential to be synthesized by typical methods. By adjusting the different sputtering processes, the composition of each element in $\mathrm{Nb}-\mathrm{Si}-\mathrm{C}$ thin film can be adjusted; the film with better performance can then be prepared, and it is possible to prepare a new MAX phase of Nb-Si-C system. Researchers often employ the following two process adjustments: the first is to adjust the sputtering power; the second is to adjust the area ratio of the target material to be similar to the stoichiometric ratio of the MAX phase.

The purpose of this research was to deposit $\mathrm{Nb}-\mathrm{Si}-\mathrm{C}$ thin films from three separate $\mathrm{Nb}, \mathrm{Si}$, and $\mathrm{C}$ targets using radio frequency magnetron sputtering at low temperatures through different power. The microstructure, composition, and properties of the deposited $\mathrm{Nb}$-Si-C thin films were investigated by X-ray diffraction (XRD), X-ray photoelectron spectroscopy (XPS), scanning electron microscopy (SEM), energy dispersive spectrometer (EDS), atomic force microscopy (AFM), nano-indentation, and four-point-probe resistance tester. Another purpose of the research was to find sputtering technology that could prepare a new MAX phase.

\section{Materials and Methods}

$\mathrm{Nb}$-Si-C films were deposited by radio frequency magnetron sputtering using (the JGP450-PECVD200 magnetron sputtering apparatus, SKY, Shenyang, China) from three separate targets at $25^{\circ} \mathrm{C}$. The working gas of the deposition was Ar gas. Single-crystalline $\mathrm{Si}(001)$ wafers were selected as substrate for deposition of $\mathrm{Nb}-\mathrm{Si}-\mathrm{C}$ films. Their size was $10 \mathrm{~mm} \times 10 \mathrm{~mm} \times 1.5 \mathrm{~mm}$. Substrate of $\mathrm{Si}(001)$ was cleaned in acetone, ethanol, and deionized water for $10 \mathrm{~min}$ to remove dust and impurities from the surface. The cleaned substrate was dried to keep the surface clean during the process, and the substrate was placed into a drying dish.

A slice of $\mathrm{Si}(99.99 \%)$ and three slices of graphite $(99.99 \%)$ targets were stuck on a circular slice of $\mathrm{Nb}(99.95 \%)$ in the area ratio of $1(\mathrm{Si}): 3(\mathrm{C}): 5(\mathrm{Nb})$. We hoped that the percentage of elements in the film after sputtering would be similar to that of the $\mathrm{Nb}_{4} \mathrm{SiC}_{3} \mathrm{MAX}$ phase. The Si target was $10 \mathrm{~mm} \times 5 \mathrm{~mm} \times 1.5 \mathrm{~mm}$, the $C$ target was $10 \mathrm{~mm} \times 5 \mathrm{~mm} \times 1 \mathrm{~mm}$, and the $\mathrm{Nb}$ target was $12 \mathrm{~mm}$ in radius and $3 \mathrm{~mm}$ thick. The distance between the substrates and the targets was $60 \mathrm{~mm}$. The vacuum chamber was pumped to a pressure of $3.0 \times 10^{-5} \mathrm{~Pa}$. Then, a certain amount of Ar gas was introduced to control the cavity pressure at 1.0 Pa. In order to remove contaminants from the substrate, it was presputtered by Ar ions at a bias voltage of $-200 \mathrm{~V}$ for $15 \mathrm{~min}$. The working pressure of $\mathrm{Ar}(99.999 \%)$ was $2.4 \mathrm{~Pa}$ and the flow rate was $25 \mathrm{sccm}$. The bias voltage was $-100 \mathrm{~V}$, as shown in Table 1. 
Table 1. Fixed parameters in sputtering deposition.

\begin{tabular}{ccccc}
\hline $\begin{array}{c}\mathrm{Si} / \mathrm{C} / \mathrm{Nb} \\
\text { Area Ratio }\end{array}$ & $\begin{array}{c}\text { Ar Gas Flow } \\
\text { Rate (sccm) }\end{array}$ & $\begin{array}{c}\text { Sputtering } \\
\text { Pressure (Pa) }\end{array}$ & $\begin{array}{c}\text { Vacuum Degree } \\
\mathbf{( P a )}\end{array}$ & $\begin{array}{c}\text { Base Bias } \\
\text { (v) }\end{array}$ \\
\hline $1: 3: 5$ & 25 & 2.4 & $3 \times 10^{-5}$ & -100 \\
\hline
\end{tabular}

The binding force of the elements varied with sputtering power. By adjusting the sputtering power of $\mathrm{Nb}$ target and $\mathrm{Si}$ target, $\mathrm{Nb}-\mathrm{Si}-\mathrm{C}$ composite films with very different structures and properties were prepared. The researchers also found that the fiber structure of the film was very sensitive to changes in Si content [25]. Some scholars changed the content of silicon in the deposited film by the number of Si plates affixed to the niobium target [32].

To investigate the impact of sputtering power, $\mathrm{Nb}-\mathrm{Si}-\mathrm{C}$ thin films specimens were synthesized at five different sputtering powers: $65,70,75,80$, and $100 \mathrm{~W}$. The sputtering time for all specimens was $60 \mathrm{~min}$. The sputtering time and sputtering power for each group of parameters (from a to e) are shown in Table 2.

Table 2. Process parameters used in sputter deposition.

\begin{tabular}{cccccc}
\hline Process Parameters & a & b & c & d & e \\
\hline Sputtering time $(\min )$ & 60 & 60 & 60 & 60 & 60 \\
Sputtering Power $(W)$ & 65 & 70 & 75 & 80 & 100 \\
\hline
\end{tabular}

The structure of the thin films was characterized by X-ray diffraction (XRD, Panalytical, Almelo, The Netherlands) with a CuK $\alpha$ radiation source $(\lambda=0.14505)$. The measurements were taken over a detection range of $\theta-2 \theta$ with a step of $0.02^{\circ}$. The acceleration voltage was $40 \mathrm{kV}$, and the current was $40 \mathrm{~mA}$. The composition and chemical states of the thin films were analyzed by X-ray photoelectron spectroscopy (XPS, Thermo Fisher Scientific, Waltham, MA, USA) with a AlK $\alpha$ source.

The microstructure of the films was observed with scanning electron microscopy (SEM, Thermo Fisher Scientific, Waltham, MA, USA) and atomic force microscopy (AFM, Bruker, Karlsruhe, Germany). Energy dispersive spectrometer (EDS, Thermo Fisher Scientific, Waltham, MA, USA) was used to measure the chemical composition of the films, the acceleration voltage was $20 \mathrm{kV}$. The electrical resistivity of the thin films was tested with a four-point probe resistance tester. Nano hardness and elastic modulus of the films were measured by nano-indentation. The test adopted continuous stiffness measurement technology (CSM) with a Berkovich indenter, (Agilent Technologies, Palo Alto, CA, USA). The indenter was pressed to a depth of $200 \mathrm{~nm}$ with a load time of $10 \mathrm{~s}$. In order to reduce the error, we carried out the process five times at different parts on each film and then took the average value of the five measurements as the hardness of each film.

\section{Results and Discussion}

Figure 1 shows the $\mathrm{X}$-ray diffraction results of the five deposited thin films (a to e) from $\mathrm{Nb}, \mathrm{Si}$, and $\mathrm{C}$ targets onto $\mathrm{Si}(100)$ substrates with a sputtering power from $65-100 \mathrm{~W}$ and a sputtering time of $60 \mathrm{~min}$.

For film a, there are four diffraction peaks in the figure, including $\mathrm{SiC}$ peaks at $35.2^{\circ}$, $61.0^{\circ}, 72.5^{\circ}$, and an undesignated diffraction peak at $42.3^{\circ}$. According to the analysis of the three targets, it is also possible that these diffraction peaks represent a new Nb-Si-C ternary compound. To verify this hypothesis, we refer to the research literature on the calculation of the $\mathrm{Nb}$-Si-C MAX phase, which used density functional theory with generalized gradients to simulate the XRD patterns of the $\mathrm{Nb}_{4} \mathrm{SiC}_{3} \mathrm{MAX}$ phase [31]. After comparison with this experiment's XRD pattern, it was found that the three strongest peaks in the experimental were in good agreement with the simulated data (the vertical marks), so it can be assumed that there was a $\mathrm{Nb}_{4} \mathrm{SiC}_{3} \mathrm{MAX}$ phase in film a. For films $\mathrm{b}$ to e, only two kinds of diffraction 
peaks could be found, corresponding to $\mathrm{NbC}$ and $\mathrm{SiC}$. From the diffraction results, it can be observed that when the sputtering power is higher than $70 \mathrm{~W}, \mathrm{Nb}-\mathrm{Si}-\mathrm{C}$ system ternary compounds are not formed.

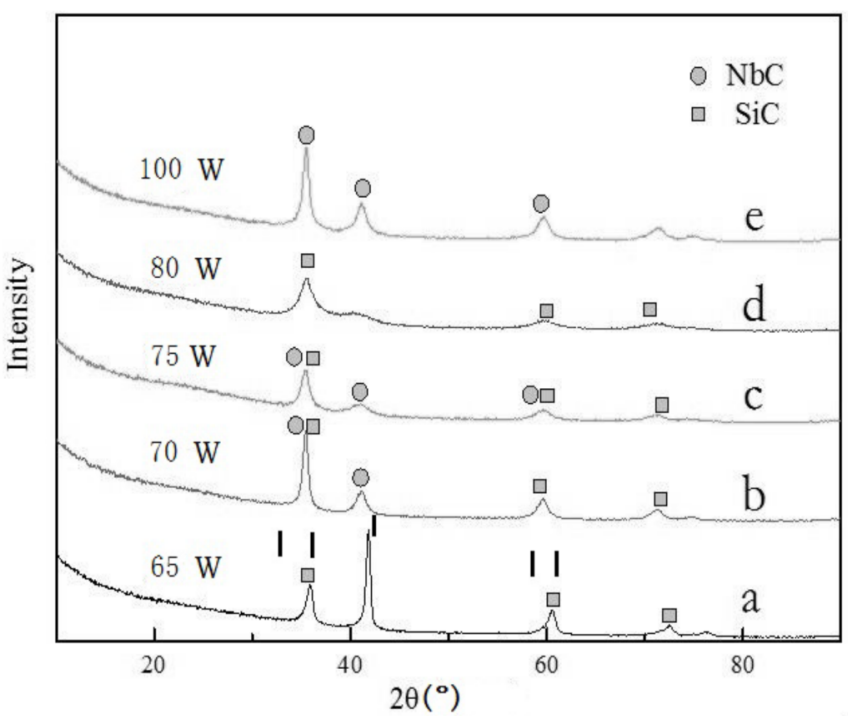

Figure 1. X-ray diffraction patterns of the five deposited thin films (a to e). The vertical marks are the simulated XRD peaks of $\mathrm{Nb}_{4} \mathrm{SiC}_{3}$ phase. The three strongest peaks in the experiment are in good agreement with the simulated data.

Table 3 shows the EDS composition analysis results of the thin films (from a to e). It can be seen that with the increase of sputtering power, the atomic percentage of $\mathrm{C}$ increases continuously, from $30 \%$ to $44 \%$. The atomic content of Si decreases continuously, from $25 \%$ to $15 \%$, while the atomic content of $\mathrm{Nb}$ fluctuates within a certain range.

Table 3. EDS composition analysis results of the thin films (from a to e).

\begin{tabular}{cccc}
\hline Sputtering Power (W) & C (at.\%) & Si (at.\%) & Nb (at.\%) \\
\hline $65(\mathrm{a})$ & $30 \pm 1.6$ & $25 \pm 1.7$ & $45 \pm 0.5$ \\
$70(\mathrm{~b})$ & $36 \pm 1.8$ & $23 \pm 1.3$ & $41 \pm 0.6$ \\
$75(\mathrm{c})$ & $42 \pm 1.6$ & $21 \pm 1.6$ & $37 \pm 0.7$ \\
$80(\mathrm{~d})$ & $40 \pm 1.8$ & $18 \pm 1.5$ & $42 \pm 0.5$ \\
$100(\mathrm{e})$ & $44 \pm 2.1$ & $15 \pm 1.7$ & $41 \pm 0.4$ \\
\hline
\end{tabular}

Combined with the previous analysis of the composition of the films, with the increase of sputtering power, the content of $C$ element in the film increases gradually, and the number of $\mathrm{Nb}-\mathrm{C}$ compounds in the coating increases. At this time, the Si element is difficult to insert into $\mathrm{Nb}-\mathrm{C}$ compounds with strong bond energy, and it can be considered that the formation of $\mathrm{Nb}_{4} \mathrm{SiC}_{3} \mathrm{MAX}$ is inhibited to some extent by the increase of $\mathrm{Nb}-\mathrm{C}$ compounds.

$X$-ray photoelectron spectroscopy was used to investigate the undesignated diffraction peaks in film a. The data obtained were analyzed with XPSPEAK software (version 4.0, Hong Kong, China), and the narrow scan peaks of $\mathrm{Nb} 4 \mathrm{~d}, \mathrm{Si} 3 \mathrm{p}$, and C $2 \mathrm{p}$ were fitted with different peaks. As shown in Figure 2, there are two peaks in Nb4d (206.8, 209.2 eV). The $\mathrm{Nb}$-Si-C film correlation calculation indicates that some $\mathrm{Nb}$ is bonded to $\mathrm{C}$, and the rest is bonded to Si. There is one peak in Si3p $(106.4 \mathrm{eV})$, indicating $\mathrm{Nb}$ is bonded to Si. There is one peak in $\mathrm{C} 2 \mathrm{p}(284.5 \mathrm{eV})$, indicating $\mathrm{Nb}$ is bonded to $\mathrm{C}$. 

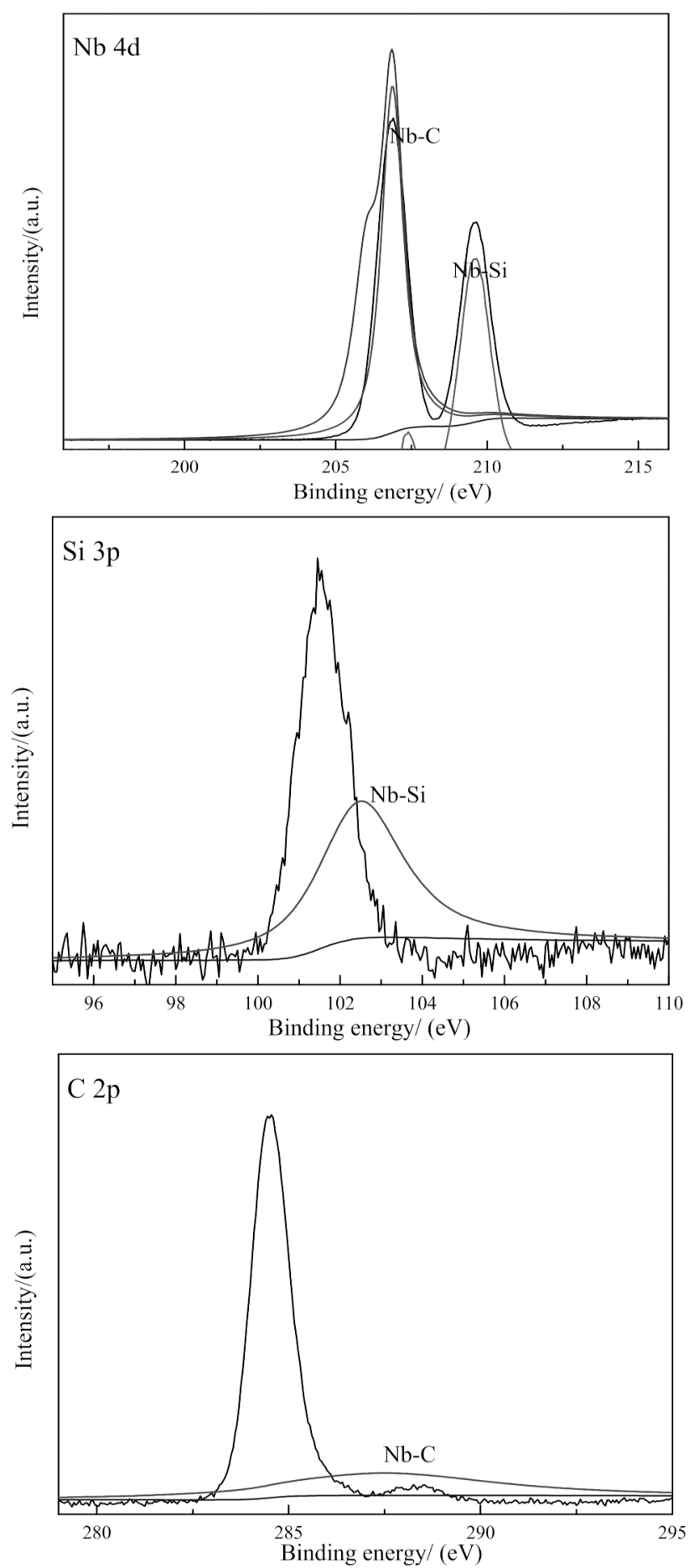

Figure 2. X-ray photoelectron spectroscopy for film a.

These experimental results, combined with preliminary studies on $\mathrm{Nb}_{4} \mathrm{AC}_{3} \mathrm{MAX}$ phases using density functional theory, indicate that the phase of the new thin film could be $\mathrm{Nb}_{4} \mathrm{SiC}_{3}$. Until now, there have been no reports on the preparation of $\mathrm{Nb}_{4} \mathrm{SiC}_{3} \mathrm{MAX}$ phase.

The five deposited thin films (from a to e) were observed with a scanning electron microscope. Figure 3 shows that the surfaces of the experimentally synthesized films are dense, homogenous, and crack free; they are also observed to be polycrystal. Figure 4 shows a cross-sectional of film a; the thickness of the film was about $270 \mathrm{~nm}$. Figure 5 shows the AFM 3D morphology of film a; the roughness value of the film is $1.68 \mathrm{~nm}$. 
The surface is smooth and the roughness is small, which indicates that the film has good wear resistance.

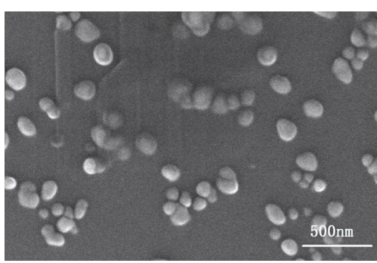

(a)

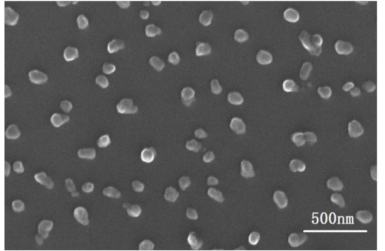

(d)

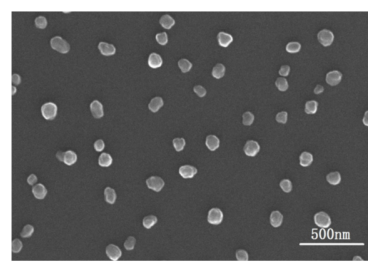

(b)

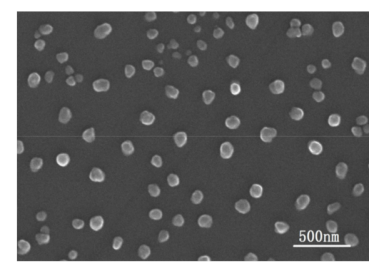

(c)

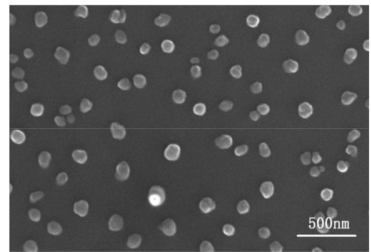

(e)

Figure 3. SEM images of the thin films deposited at $25^{\circ} \mathrm{C}$ for $60 \mathrm{~min}$ with different power: (a) $65 \mathrm{~W}$, (b) $70 \mathrm{~W},(\mathbf{c}) 75 \mathrm{~W},(\mathbf{d}) 80 \mathrm{~W}$, and (e) $100 \mathrm{~W}$.

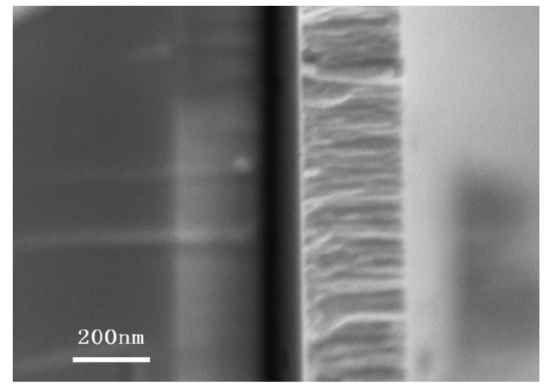

Figure 4. Cross-sectional image of thin film a deposited at $25^{\circ} \mathrm{C}$ for $60 \mathrm{~min}$ with $65 \mathrm{~W}$.
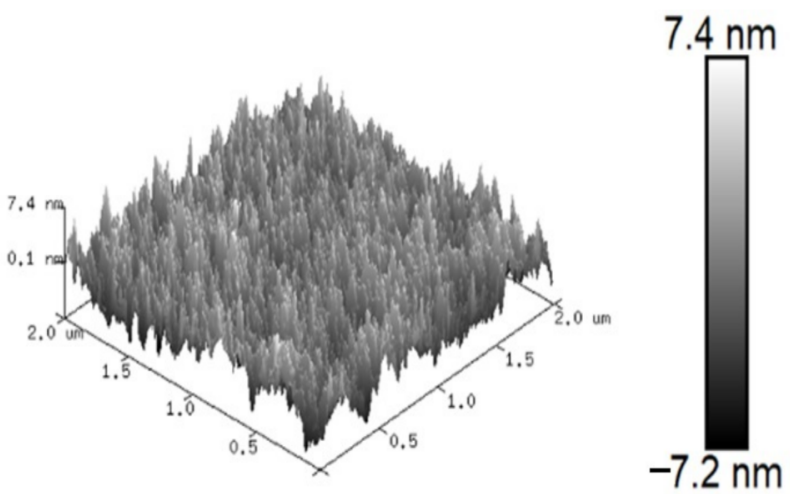

Figure 5. The AFM 3D micrograph of the thin film a deposited at $25{ }^{\circ} \mathrm{C}$ for 60 min with $65 \mathrm{~W}$. The roughness value of film a is $1.68 \mathrm{~nm}$.

Electrical conductivity tests using the RTS-9 double-resistance four-probe test were carried out, and the electrical resistivity of the synthetic films a to e ranged from 0.79 to $2.2 \mu \Omega \cdot \mathrm{m}$. As shown in Table 4, when the power was $65 \mathrm{~W}$, the electrical resistivity of film a was $0.99 \mu \Omega \cdot m$. When the power is greater than $65 \mathrm{~W}$ (films from b to e), the electrical resistivity was in turn $1.95,2.06,1.89$, and $2.20 \mu \Omega \cdot \mathrm{m}$ respectively. Analysis showed that the resistivity of film a was lower than that of other samples, which can indirectly prove that film a generated $\mathrm{Nb}_{4} \mathrm{SiC}_{3} \mathrm{MAX}$ phase. This was also consistent with the relevant literature, which indicates that MAM phase was a good conductor of electricity and that the room 
temperature resistivity generally ranged from 0.07 to $2 \mu \Omega \cdot \mathrm{m}$. Many MAX materials have an even lower resistivity than titanium [33].

Table 4. Mechanical properties and electrical resistivity of the thin films.

\begin{tabular}{cccc}
\hline $\begin{array}{c}\text { Sputtering Power } \\
(\mathbf{W})\end{array}$ & $\begin{array}{c}\text { Hardness } \\
(\mathbf{G P a})\end{array}$ & $\begin{array}{c}\text { Elastic Modulus } \\
(\mathbf{G P a})\end{array}$ & $\begin{array}{c}\text { Resistivity } \\
(\boldsymbol{\mu} \boldsymbol{\Omega} \cdot \mathbf{m})\end{array}$ \\
\hline $65(\mathrm{a})$ & $15 \pm 1$ & $200 \pm 16$ & 0.99 \\
$70(\mathrm{~b})$ & $18 \pm 1$ & $215 \pm 10$ & 1.95 \\
$75(\mathrm{c})$ & $19 \pm 1$ & $200 \pm 17$ & 2.06 \\
$80(\mathrm{~d})$ & $20 \pm 1$ & $220 \pm 15$ & 1.89 \\
$100(\mathrm{e})$ & $20 \pm 2$ & $215 \pm 13$ & 2.20 \\
\hline
\end{tabular}

Nano-hardness and elastic modulus of films deposited with different power were tested by a nano-indentation instrument. As shown in Table 4, when the power was $65 \mathrm{~W}$, the nano-hardness and elastic modulus of the film were 15 and $200 \mathrm{GPa}$. When the power was greater than $65 \mathrm{~W}$, the hardnesses of the films were from 18 to $20 \mathrm{GPa}$, and the elastic moduli were from 200 to $220 \mathrm{GPa}$. It can be seen from the nano-hardness test that when the power was $65 \mathrm{~W}$, the hardness of the film was far less than that of the other films; the main reason could be the formation of $\mathrm{Nb}_{4} \mathrm{SiC}_{3} \mathrm{MAX}$ phase in the film, as its hardness is far lower than the binary $\mathrm{Nb}-\mathrm{C}$ ceramic phase. It is suggested in some literature that if the ratio of hardness to elastic modulus $(H / E)$ is higher, the film can obtain higher wear resistance. According to the experimental data, film a has an $H / E$ value of 0.075 ; the values of films $\mathrm{b}$ to e are $0.084,0.095,0.091$, and 0.093, respectively. Based on this result, it indicates that among the five sputtering films, the wear resistance of film $\mathrm{c}$ is the highest, while that of film $\mathrm{a}$ is the lowest. By adjusting the sputtering power of $\mathrm{Nb}-\mathrm{Si}-\mathrm{C}$ film and changing the proportion of three elements, the film with the best wear resistance can be achieved.

As for the mechanical properties of $\mathrm{Nb}-\mathrm{Si}-\mathrm{C}$ thin films, some scholars believe that the hardness of $\mathrm{Nb}-\mathrm{Si}-\mathrm{C}$ thin films will decrease with the generation of more $\mathrm{Si}-\mathrm{C}$ phase in the film and that the increase of the amorphous phase caused by $\mathrm{Si}$ in ternary films is also a way to reduce the hardness [32].

\section{Conclusions}

In conclusion, we synthesized $\mathrm{Nb}-\mathrm{Si}-\mathrm{C}$ thin films by radio frequency magnetron sputtering. The results show that the microstructure and properties of the films were closely related to the deposition power. When the deposition power was greater than $70 \mathrm{~W}$, the deposited films were mainly $\mathrm{NbC}$ and $\mathrm{SiC}$ phases. When the deposition power was $65 \mathrm{~W}$, a new ternary phase was formed in the thin film in addition to the $\mathrm{NbC}$ and $\mathrm{SiC}$ phases. Based on the analysis of the experiment and the comparison with the results of the structural calculation, we predict that the ternary $\mathrm{Nb}-\mathrm{Si}-\mathrm{C}$ compound might be $\mathrm{Nb}_{4} \mathrm{SiC}_{3}$ phase. The formation of ternary compounds is related to the content of $\mathrm{C}$ and $\mathrm{Si}$ in the sputtering process. Excessive $\mathrm{C}$ content will hinder the formation of ternary compounds.

According to the four-point probe test, $\mathrm{Nb}-\mathrm{Si}-\mathrm{C}$ thin films have relatively low resistivity. Moreover, they also have high hardness and elastic modulus. Based on the above properties, $\mathrm{Nb}-\mathrm{Si}-\mathrm{C}$ thin films can be used to make electrical contacts and thermal printing heads.

This study suggests that different sputtering power can be used to prepare $\mathrm{Nb}-\mathrm{Si}-\mathrm{C}$ thin films with different properties and that $\mathrm{Nb}_{4} \mathrm{SiC}_{3}$ phase can be prepared at lower power. Finally, we believe that single-phase $\mathrm{Nb}_{4} \mathrm{SiC}_{3}$ thin film can be prepared by proper sputtering technology. The preparation of single-phase $\mathrm{Nb}_{4} \mathrm{SiC}_{3}$ thin film and the evaluation of their properties should be further studied in future.

Author Contributions: Data curation, G.L. (Guanqi Liu); project administration, X.Z.; supervision, Y.F.; writing—original draft, Z.L.; writing—review and editing, G.L. (Guotan Liu). All authors have read and agreed to the published version of the manuscript. 
Funding: This study was supported by the Chinese marine low-speed diesel engine project, Grant No. CDGC01-KT0302.

Institutional Review Board Statement: Not applicable.

Informed Consent Statement: Not applicable.

Data Availability Statement: Data is contained within the article.

Acknowledgments: The authors thank the staff of the Key Laboratory of Superlight Materials and Surface Technology at Harbin Engineering University.

Conflicts of Interest: The authors declare no conflict of interest.

\section{References}

1. Barsoum, M.W. The $\mathrm{M}_{n+1} \mathrm{AX}_{n}$ Phases: A new class of solids. Progr. Solid S.T. Chem. 2000, 28, 201-281. [CrossRef]

2. Eklund, P.; Beckers, M.; Jansson, U.; Högberg, H.; Hultman, L. The $\mathrm{M}_{n+1} \mathrm{AX}$ n phases: Materials science and thin-film processing. Thin Solid Film. 2010, 518, 1851-1878. [CrossRef]

3. Sun, Z.M. Progress in research and development on MAX phases: A family of layered ternary compounds. Int. Mater. Rev. 2011, 56, 143-166. [CrossRef]

4. Barsoum, M.W. MAX Phases: Properties of Machinable Ternary Carbides and Nitrides; Wiley-VCH Verlag GmbH \& Co.: Weinheim, Germany, 2013; pp. 1-2.

5. Ward, J.; Middleburgh, S.; Topping, M.; Garner, A.; Stewart, D.; Barsoum, M.W.; Preuss, M.; Frankel, P. Crystallographic evolution of max phases in proton irradiating environments. J. Nucl. Mater. 2018, 502, 220-227. [CrossRef]

6. Wang, J.; Zhou, Y. Recent progress in theoretical prediction, preparation, and characterization of layered ternary transition-metal carbides. Annu. Rev. Mater. Res. 2009, 39, 415-443. [CrossRef]

7. Palmquist, J.-P.; Li, S.; Persson, P.O.Å.; Emmerlich, J.; Wilhelmsson, O.; Högberg, H.; Katsnelson, M.I.; Johansson, B.; Ahuja, R.; Eriksson, O.; et al. $\mathrm{M}_{n+1} \mathrm{AX}_{n}$ phases in the Ti-Si-C system studied by thin-film synthesis and Ab initio calculations. Phys. Rev. $B$ 2004, 70, 165401. [CrossRef]

8. Eklund, P.; Beckers, M.; Frodelius, J.; Högberg, H.; Hultman, L. Magnetron sputtering of $\mathrm{Ti}_{3} \mathrm{SiC}_{2}$ thin films from a compound target. J. Vac. Sci. Technol. A 2007, 25, 1381-1388. [CrossRef]

9. Furgeaud, C.; Brenet, F.; Nicolai, J. Multi-scale study of $\mathrm{Ti}_{3} \mathrm{SiC}_{2}$ thin film growth mechanisms obtained by magnetron sputtering. Materialia 2019, 7, 100369. [CrossRef]

10. Palmquist, J.-P.; Jansson, U.; Seppänen, T.; Persson, P.O.Å.; Birch, J.; Hultman, L.; Isberg, P. Magnetron sputtered epitaxial single-phase $\mathrm{Ti}_{3} \mathrm{SiC}_{2}$ thin films. Appl. Phys. Lett. 2002, 81, 835-837. [CrossRef]

11. Zhang, Z.; Jin, H.; Chai, J.; Pan, J.; Seng, H.L.; Goh, G.T.W.; Wong, L.M.; Sullivan, M.B.; Wang, S.J. Temperature-dependent microstructural evolution of $\mathrm{Ti}_{2} \mathrm{AlN}$ thin films deposited by reactive magnetron sputtering. Appl. Surf. Sci. 2016, 368, 88-96. [CrossRef]

12. Joelsson, T.; Flink, A.; Birch, J.; Hultman, L. Deposition of single-crystal $\mathrm{Ti}_{2} \mathrm{AlN}$ thin films by reactive magnetron sputtering from a 2Ti:Al Compound Target. J. Appl. Phys. 2007, 102, 074918. [CrossRef]

13. Höglund, C.; Beckes, M.; Schell, N.; von Borany, J.; Birch, J.; Hultman, L. Topotaxial growth of Ti 2 AlN by solid state reaction in AlN/Ti. Appl. Phys. Lett. 2007, 90, 174106. [CrossRef]

14. Wang, T.; Chen, Z.; Wang, G.; Wang, L.; Zhang, G.J. Microstructure evolution of polycrystalline Ti ${ }_{2} \mathrm{AlN}$ MAX phase film during post-deposition annealing. J. Eur. Ceram. Soc. 2018, 38, 4892-4898. [CrossRef]

15. Wilhelmsson, O.; Palmquist, J.-P.; Lewin, E.; Emmerlich, J.; Eklund, P.; Persson, P.O.Å.; Högberg, H.; Li, S.; Ahuja, R.; Eriksson, O.; et al. Deposition and characterization of ternary thin films within the Ti-Al-C system by DC magnetron sputtering. J. Cryst. Growth 2006, 291, 290-300. [CrossRef]

16. Su, R.; Zhang, H.; O'Connor, D.J.; Shi, L.; Meng, X.; Zhang, H. Deposition and characterization of $\mathrm{Ti}_{2} \mathrm{AlC}_{\mathrm{MAX} P h a s e}$ and Ti ${ }_{3} \mathrm{AlC}$ thin films by magnetron sputtering. Mater. Lett. 2016, 179, 194-197. [CrossRef]

17. Wang, Z.; Li, W.; Wang, C.; Wu, H.C.; Ke, P.L.; Wang, A.Y. Transforming the amorphous Ti-Al-C coatings to high-purity Ti ${ }_{2} \mathrm{AlC}$ MAX phase coatings by prolonged annealing at $550{ }^{\circ} \mathrm{C}$. Mater. Lett. 2020, 261, 127160. [CrossRef]

18. Högberg, H.; Eklund, P.; Emmerlich, J.; Birch, J.; Hultman, L. Epitaxial $\mathrm{Ti}_{2} \mathrm{GeC}_{1} \mathrm{Ti}_{3} \mathrm{GeC}_{2}$, and $\mathrm{Ti}_{4} \mathrm{GeC}_{3} \mathrm{MAX}_{\text {-phase thin films }}$ grown by magnetron sputtering. J. Mater. Res. 2005, 20, 779-782. [CrossRef]

19. Crisan, O.; Crisan, A.D. Incipient low-temperature formation of MAX phase in Cr-Al-C films. J. Adv. Ceram. 2018, 7, 143-151. [CrossRef]

20. Grieseler, R.; Hähnlein, B.; Stubenrauch, M.; Kups, T.; Wilke, M.; Hopfeld, M.; Pezoldt, J.; Schaaf, P. Nanostructured plasma etched, magnetron sputtered nanolaminar $\mathrm{Cr}_{2}$ AlC MAX phase thin films. Appl. Surf. Sci. 2014, 292, 997-1001. [CrossRef]

21. Li, C.; Wang, B.; Li, Y.; Wang, R. First-principles study of electronic structure, mechanical and optical properties of $\mathrm{V}_{4} \mathrm{AlC}_{3}$. $J$. Phys. D: Appl. Phys. 2009, 42, 065407. [CrossRef]

22. Li, Y.; Qian, Y.; Zhao, G.; Xu, J.; Li, M. Preparation of $\mathrm{Nb}_{2} \mathrm{AlC}$ Coating by DC magnetron sputtering and subsequent annealing. Ceram. Int. 2017, 43, 6622-6625. [CrossRef] 
23. Tengstrand, O.; Nedfors, N.; Andersson, M.; Lu, J.; Jansson, U.; Flink, A.; Eklund, P.; Hultman, L. Beam-induced crystallization of amorphous Me-Si-C (Me = Nb or Zr) thin films during transmission electron microscopy. Mrs Commun. 2013, 3, 151-155. [CrossRef]

24. Tengstrand, O.; Nedfors, N.; Andersson, M.; Lu, J.; Jansson, U.; Flink, A.; Eklund, P.; Hultman, L. Model for electron-beam-induced crystallization of amorphous Me-Si-C (Me $=\mathrm{Nb}$ or $\mathrm{Zr}$ ) thin films. J. Mater. Res. 2014, 14, 2854-2862. [CrossRef]

25. Nedfors, N.; Tengstrand, O.; Flink, A.; Eklund, P.; Hultman, L.; Jansson, U. Characterization of amorphous and nanocomposite $\mathrm{Nb}-\mathrm{Si}-\mathrm{C}$ thin films deposited by DC magnetron sputtering. Thin Solid Film. 2013, 545, 272-278. [CrossRef]

26. Ying, G.B.; Ma, F.C.; Su, L.; He, X.D.; Zhang, C.; Dai, Z.H.; Luo, H.; Du, S.Y.; Wang, C. An ab initio prediction study of the electronic structure and elastic properties of $\mathrm{V}_{3} \mathrm{GeC}_{2}$. Process. Appl. Ceram. 2017, 11, 82-86. [CrossRef]

27. Faraoun, H.I.; Abderrahim, F.Z.; Esling, C. First principle calculations of MAX ceramics $\mathrm{Cr}_{2} \mathrm{GeC}_{2} \mathrm{~V}_{2} \mathrm{GeC}$ and their substitutional solid solutions. Comput. Mater. Sci. 2013, 74, 40-49. [CrossRef]

28. Yi, J.X.; Chen, P.; Li, D.L.; Xiao, X.B.; Zhang, W.B.; Tang, B.Y. Elastic and electronic properties of a new MAX compound from first-principles calculations. Solid State Commun. 2010, 150, 49-53. [CrossRef]

29. Ghebouli, B.; Ghebouli, M.A.; Fatmi, M.; HI, T.C.; Bouhemadou, A. First-principles calculations of structural, electronic, elastic and thermal properties of phase $\mathrm{M}_{2} \mathrm{SiC}(\mathrm{M}=\mathrm{Ti}, \mathrm{V}, \mathrm{Cr}, \mathrm{Zr}, \mathrm{Nb}, \mathrm{Mo}, \mathrm{Hf}$, Ta and W). Trans. Nonferrous Met. Soc. China 2015, 25, $915-925$. [CrossRef]

30. Li, C.L.; Kuo, J.L.; Wang, B.; Li, Y.S.; Wang, R. A new layer compound $\mathrm{Nb}_{4} \mathrm{SiC}_{3}$ predicted from first-principles theory. J. Phys. D Appl. Phys. 2009, 42, 075404. [CrossRef]

31. Fu, Y.D.; Wang, B.C.; Teng, Y.; Zhu, X.S.; Feng, X.X.; Yan, M.F.; Korzhavyi, P.; Sun, W.W. The Role of group III, IV elements in $\mathrm{Nb}_{4} \mathrm{AC}_{3}$ MAX phases $(\mathrm{A}=\mathrm{Al}, \mathrm{Si}, \mathrm{Ga}, \mathrm{Ge})$ and the unusual anisotropic behavior of the electronic and optical properties. Phys. Chem. Chem. Phys. 2017, 19, 15471. [CrossRef]

32. Onoprienko, A.A.; Ivashchenko, V.I.; Timofeeva, I.I.; Sinelnitchenko, A.K.; Butenko, O.A. Experimental and theoretical investigation of Nb-Si-C films. Surf. Coat. Technol. 2016, 300, 35-41. [CrossRef]

33. El-Raghy, T.; Chakraborty, S.; Barsoum, M.W. Synthesis and characterization of $\mathrm{Hf}_{2} \mathrm{PbC}, \mathrm{Zr}_{2} \mathrm{PbC}$ andM $2 \mathrm{SnC}(\mathrm{M}=\mathrm{Ti}, \mathrm{Hf}, \mathrm{Nb}$ or Zr). J. Eur Ceram. Soc. 2000, 20, 2619-2625. [CrossRef] 